\title{
Obesity and diabetes among children: Nutrition-related educational and practical barriers and future opportunities
}

\author{
Gillian Mandich and Leigh Vanderloo
}

\section{University of Western Ontario}

For the first time in history, parents are expected to outlive their children. ${ }^{1}$ This statement reflects Canada's current obesity epidemic, during which obesity rates have tripled over the past thirty years. ${ }^{2}$ The rates of type 2 diabetes have also significantly increased within the Canadian population (from $4.2 \%$ in 2000 to $7.3 \%$ in 2010). ${ }^{3}$ Consequently, there is a clear need to address both obesity and diabetes, particularly given their strong correlation. ${ }^{3}$ Physical activity and dietary intake represent two modifiable behaviours associated with obesity and diabetes; this paper will address dietary intake by examining two nutrition-related barriers that inhibit children's health and will suggest potential solutions.

\section{Parents/Guardians: Problems and Potential}

Ideally, parents/guardians (hereafter used interchangeably) would model healthy food choices and create supportive home environments that normalize healthy eating. However, a barrier facing children in achieving a wellbalanced diet is the absence of strong parental role models. ${ }^{4}$ Children tend to mimic their guardians' nutritional choices, good or bad, ${ }^{5}$ and adults should be mindful of the impact their nutrition-related actions have on their children's food choices and perceptions of 'normal' eating.

Given the strong influence parents have over their children's lifestyle choices, coupled with their control of foods entering the home, a family approach to addressing home-based dietary choices seems important. One solution is to schedule regular family mealtimes. ${ }^{5}$ Given that food preferences and eating habits are formed at a young age, ${ }^{6}$ consuming meals as a family can provide opportunities for parental modeling and can promote healthy choices. Further, including children in daily meal preparation early on, and at a level suitable for their age - from the job of choosing one of dinner's vegetable options, helping to garnish the meal to look attractive, or peeling/washing fruits for dessert - is also a creative and important approach to generating interest and normalizing involvement in healthy food preparation. ${ }^{6,7}$ Without opportunities to contribute to dietary choices and practice food skills at an early age, children's confidence in making healthy food choices can be hampered long-term. Additionally, insufficient nutritional education among parents may lead to the exchange of inaccurate information with their children. Guardians need to be armed with appropriate knowledge and be supported in their efforts of raising healthy children. Opportunities for nutrition-based learning need to be provided to parents in a variety of formats, such as workshops, television segments, seminars, or practical written tips sent home from schools.

\section{Nutrition-Related Knowledge: Inadequacies and Instructional Opportunities}

Lack of nutrition knowledge is a second barrier preventing children from making healthy dietary choices. ${ }^{4}$ In fact, researchers have promoted nutrition education as the first line of defence for children with type 2 diabetes. ${ }^{7}$ Within a context of challenging physical and social environmental influences, such as the overabundance of unhealthy food options and junk-food marketing targeted at youth, ${ }^{8}$ children often lack knowledge to make healthy choices. For example, a recent study found that many children aged $8-18$ years (54-72\%) were unaware that trans-fatty acids were in processed foods, including French fries. ${ }^{9}$ Fortunately, suitable nutrition education can translate into positive lifestyle changes, given the demonstrated correlation between comprehensive nutrition education interventions and healthy food preparation practices. $^{9}$ Consequently, in addition to ensuring parents are on board, it is equally crucial that nutrition education be delivered directly to children. Recently, investigators summarized the importance of integrating 'fun' to help instil long-lasting interest in food-related knowledge and skill development. ${ }^{11}$ Engaging children in hands-on learning, such as food preparation skills, eyes-closed 'taste tests', and myth- 
busting educational activities (e.g. how much sugar in a can of pop) can be fun, entertaining ways to fully engage and motivate children to learn.

Schools present an ideal setting to teach children about nutrition. A recent meta-analysis found beneficial effects on Body Mass Index for children (6 to 12 years) when school curriculum included healthy eating. ${ }^{10}$ Researchers suggest children be taught specific nutritional information regarding portion size, healthy balanced meals, and low fat choices. ${ }^{4}$ Nutrition education is a fundamental component in the quest to help reduce childhood obesity and type 2 diabetes. Drastic measures are required, including lobbying officials for the re-introduction of cooking skills within schools and/or accessible extra-curricular food skills programs tailored to children and families. The "Cookit-Up!" program, a hands-on community-based program for youth that included guest chefs, field trips, and a combination of education and practical skill development, represents one such novel program that, given its evaluative findings in terms of cooking skills, self-esteem, and food choice improvements, may be considered as a model from which to build. ${ }^{11}$

\section{What's next?}

Obesity and diabetes currently affect the lives and positive experiences of too many Canadian children. The physical and social environments discourage children from making healthy dietary choices. That being said, parents and schools represent two important sources to help combat these issues. The evidence is clear that family support, ${ }^{5}$ combined with engaging and hands-on food-related programming for children, can help increase food knowledge and healthy choices while enhancing children's self-confidence and selfefficacy. ${ }^{12,13}$ This call to action highlights the urgent need to examine novel ways of combating these public health concerns so that children may reclaim their longevity and enjoy healthier lives.

\section{Acknowledgments}

We would like to thank Dr. Jennifer Irwin and Erin Pearson for their assistance in preparing this manuscript.

\section{References}

1. Olshansky SJ, Passoro DJ, Hershow RC, Layden J, Carnes, BA, Brody J, Hayflick L, Butler RN, Allision, DB, Ludwig, DS. A potential decline in life expectancy in the United States in the 21st century. N Engl J Med. 2005 Mar; 352(11):1138-45.

2. Shields M. Measured obesity: Overweight Canadian children and adolescents. Ottawa: Statistics Canada, Analytic Studies and Reports 2006. Report No.: 82-620-MWE2005001

3. Canadian Diabetes Association. An economic tsunami: The cost of diabetes in Canada. Toronto: Canadian Diabetes Association; 2009 Dec. 13 pg.

4. Ward-Begnoche W, Speaker S. Overweight youth: Changing behaviors that are barriers to health. J Fam Prac. 2006 Nov; 55(11):957-63.

5. Cason KL. Family mealtimes: More than just eating together. J Am Diet Assoc. 2006 Apr; 106[4]:532-33.

6. Hart KH, Herriot A, Bishop JA, Truby H. Promoting healthy diet and exercise patterns amongst primary school children: A qualitative investigation of parental perspectives. J Hum Nutr Diet. 2003 Apr; 16[2]:89-96.

7. McKnight-Menci H, Sababu S, Kelly SD. The care of children and adolescents with type 2 diabetes. J Pediatr Nurs. 2005 Apr; 20[2]:96-106.

8. He M, Tucker P, Irwin JD, Gilliand J, Larsen K, Hess P. Obesogenic neighbourhoods: The impact of neighbourhood restaurants and convenience stores on adolescents' food consumption behaviours. Public Health Nutri. In press 2012.

9. Shah P, Misra A, Gupta N, Hazra DK, Gupta R, Seth P, et al. Improvement in nutrition-related knowledge and behaviour of urban Asian Indian school children: Findings from the 'Medical education for children/Adolescents for Realistic prevention of obesity and diabetes and for healthy aGeing' (MARG) intervention study. Br J Nutr. 2010 Aug; 104[3]:427-36.

10. Waters E, de Silva-Sanigorski A, Hall BJ, Brown T, Campbell KJ, Gao Y, et al. Interventions for preventing obesity in children. Cochrane Database Syst Rev. 2011 Dec; 7;12:CD001871.

11. Thomas H, Irwin J. Cook It Up! A community-based cooking program for atrisk youth: Overview of a food literacy intervention. BMC Res Notes. 2011 Nov; 4(495):1-7

12. Larson NI, Story M, Eisenberg ME, Neumark-Sztainer D. Food preparation and purchasing roles among adolescents: Associations with sociodemographic characteristics and diet quality. J Am Die Assoc. 2006,106[2]:211-8.

13. Meehan M, Yeh M, Spark A. Impact of exposure to local food sources and food preparation skills on nutritional attitudes and food choices among urban minority youth. J Hunger Environ Nutr. 2008 Feb, 3[4]:456-71.

$\begin{aligned} & \text { Gillian Mandich } \\ & \text { Gillian Mandich is presently a first year PhD student at the University of Western Ontario in Health and } \\ & \text { Rehabilitation Science, Health Promotion. Gillian's research focuses on physical activity and sedentary pursuits } \\ & \text { of high-risk paediatric populations, particularly Latino and overweight/obese children. Gillian is also involved in } \\ & \text { diabetes research and currently coordinates a community-based healthy lifestyle patient-centered education } \\ & \text { program for middle (30-59) and older (60+) adults with prediabetes. }\end{aligned}$
Leigh Vanderloo
focush Vanderloo is a second year MSc student in the Health Promotion Field at the University of Western Ontario. Her research
on sedentary behaviours and healthy body weight promotion among children. In September 2012, Leigh will be starting her PhD at
the University of Western Ontario.

